\title{
Apnea Test Safety in Brain Death: A Single-Center Retrospective Cohort Analysis
}

\author{
Talita Sansoni ${ }^{\mathrm{a}}$ e, Nicholas Nascimento ${ }^{\mathrm{a}}$, Gabriel Franco ${ }^{\mathrm{b}}$, Rui Moreno ${ }^{\mathrm{c}}$, Alexandre Barros ${ }^{\mathrm{a}}$, \\ Venancio Filho ${ }^{\mathrm{d}}$, Helder Zambellid, Ana Paula Gasparotto ${ }^{\mathrm{a}}$, Luiz Antonio Sardinha ${ }^{\mathrm{d}}$, \\ Antonio Luis Falcao ${ }^{\text {a }}$
}

\begin{abstract}
Background: The apnea test, which is considered positive when no spontaneous breathing movements are observed following maximal hypercapnia $\left(\mathrm{PaCO}_{2}>55 \mathrm{~mm} \mathrm{Hg}\right)$ respiratory center stimulation, was critically evaluated in this study by assessment of blood gas analyses performed during brain death protocols from 2010 to 2017, in the intensive care units of the Universidade Estadual de Campinas (UNICAMP).

Methods: A retrospective cohort analysis based on the intensive care unit and Transplant Organ Search Organization data banks. Blood gas analyses before (pre-first and -second apnea tests) as after (afterfirst and -second apnea tests) were assessed. Descriptive statistical analyses of the numerical variables (such as $\mathrm{pH}, \mathrm{PaO}_{2}, \mathrm{PaCO}_{2}, \mathrm{HCO}_{3}$, $\mathrm{SatO}_{2}$ ) with mean values and standard deviation, medians, and quartiles were performed. The Student's $t$-test was used for pairwise group comparisons. A P $<0.05$ level was adopted for significance.
\end{abstract}

Results: Eighty-seven protocols were evaluated. The mean apnea test duration was $11 \mathrm{~min}$. All of the patients were under vasoactive drugs. Only five apnea tests were interrupted before the end at $10 \mathrm{~min}$

Manuscript submitted November 4, 2020, accepted December 24, 2020

Published online February 8, 2020

antensive Care Unit, Discipline of Physiology and Surgical Metabology, Department of Surgery, Faculty of Medical Sciences, State University of Campinas (Unicamp), Tessalia Viera de Camargo St. 126, University Town Zeferino Vaz, Campinas, Sao Paulo 13083-887, Brazil

${ }^{b}$ Department of Statistics, Instituto de Matematica, Estatistica e Computacao Cientifica da Universidade Estadual de Campinas (UNICAMP), R. Sergio Buarque de Holanda, 651 - Cidade Universitaria, Campinas-SP 13083-859, Brazil

${ }^{\mathrm{c} N e u r o c r i t i c a l}$ and Trauma Intensive Care Unit, Hospital de Sao Jose, Centro Hospitalar Universitario de Lisboa Central, Lisbon, Portugal

${ }^{\mathrm{d}}$ Transplant Organ Search Organization, Hospital das Clinicas, Universidade Estadual de Campinas (UNICAMP), Rua Tessalia Vieira de Camargo 126, Cidade Universitaria Zeferino Vaz, Campinas, Sao Paulo 13083-887, Brazil ${ }^{\mathrm{e} C}$ Corresponding Author: Talita Sansoni, Intensive Care Unit, Discipline of Physiology and Surgical Metabology, Department of Surgery, Faculty of Medical Sciences, State University of Campinas (Unicamp), Tessalia Viera de Camargo St. 126, University Town Zeferino Vaz, Campinas, Sao Paulo $13083-$ 887, Brazil. Email: tatasansoni@gmail.com

doi: https://doi.org/10.14740/jnr646 due to rapid desaturation $\left(\mathrm{SatO}_{2}<90 \%\right)$, with no invalidated apnea test. Mean and standard deviation of blood gas tests assessed before the first apnea test were: $\mathrm{pH} 7.35( \pm 0.10), \mathrm{PaO}_{2} 252.15 \mathrm{~mm} \mathrm{Hg}( \pm$ 114.11), $\mathrm{PaCO}_{2} 42.78 \mathrm{~mm} \mathrm{Hg}$ ( \pm 10.84$)$; after the first apnea test: $\mathrm{pH}$ 7.11( \pm 0.08), $\mathrm{PaO}_{2} 208.39 \mathrm{~mm} \mathrm{Hg}( \pm 112), \mathrm{PaCO}_{2} 82.43 \mathrm{~mm} \mathrm{Hg}( \pm$ 16.91); before the second test: $\mathrm{pH} 7.33( \pm 0.09), \mathrm{PaO}_{2} 253.56 \mathrm{~mm}$ $\mathrm{Hg}\left( \pm\right.$ 105.36), $\mathrm{PaCO}_{2} 43.76 \mathrm{~mm} \mathrm{Hg}$ ( \pm 9.67); following the second apnea test: $\mathrm{pH} 7.11( \pm 0.10), \mathrm{PaO}_{2} 200.1 \mathrm{~mm} \mathrm{Hg}( \pm 116.45), \mathrm{PaCO}_{2}$ $84.98 \mathrm{~mm} \mathrm{Hg}( \pm 20.21)$. The $\mathrm{pH}, \mathrm{PaO}_{2}$, and $\mathrm{PaCO}_{2}$ values before and after the first and second apnea tests have shown statistically significant differences $(\mathrm{P}<0.0001)$.

Conclusions: The apnea test was safe, blood gas test results are similar to those described in the literature, severe hypoxemias were prevented by a quick reconnection to the mechanical ventilation; and marked hypercapnia and acidemia following the apnea test were found, but no test was invalidated.

Keywords: Brain death; Brain death protocols; Apnea test; Hypercapnia; Acidemia

\section{Introduction}

After the cause of the coma is identified, the total and irreversible interruption of all brain functions means clinical and legal death [1]. During the development of this work, the diagnosis of brain death (BD) was conducted according to the the Conselho Federal de Medicina (Brazilian Federal Medical Council (CFM)) Decision No. 1,480, August 21, 1997. Once a non-reflexive coma is diagnosed, the protocol establishes that two clinical examinations should be performed, plus two apnea tests (ATs), and ancillary tests [2] with a minimum 6-h time interval for adult patients. The AT is deemed indispensable for diagnosing $\mathrm{BD}$. It should be rigorous enough to prove that there are no respiratory movements evoked by maximal respiratory center stimulation $\left(\mathrm{PaCO}_{2}>55 \mathrm{~mm} \mathrm{Hg}\right)$. Potential complications are related to harmful effects from prolonged exposure to acidemia, hypercapnia, or hypoxemia. Low blood pressure, arrhythmias, and/or hypoperfusion, which may lead to interrupting the test and impairment of organ function are mentioned. This condition may impact the quality and survival of the organs to be 


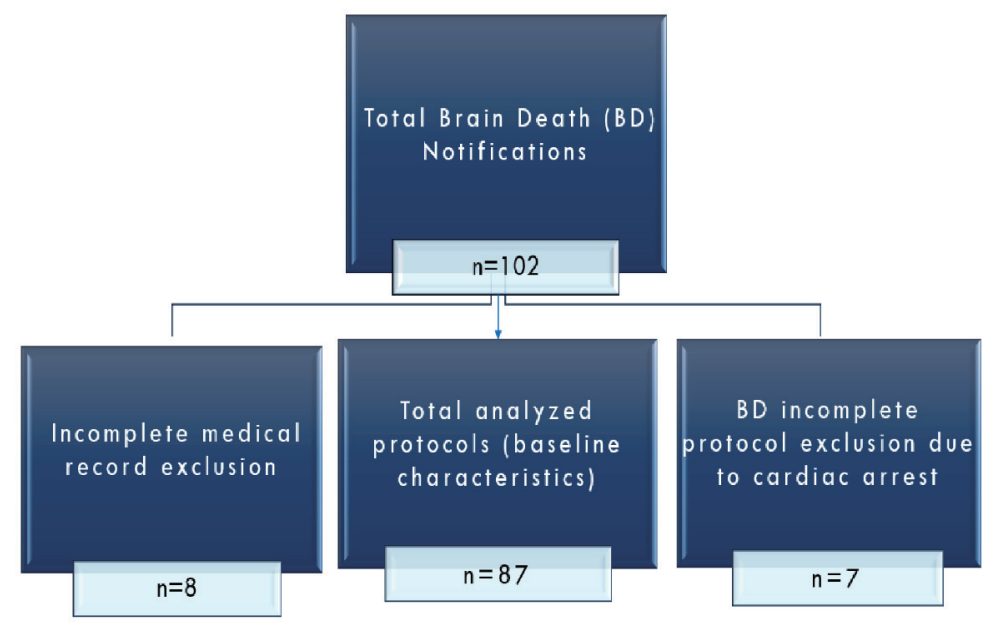

Figure 1. Flowchart of protocols.

donated [3]. In this trial, we aimed to assess the safety of ATs in patients undergoing a BD protocol.

\section{Materials and Methods}

This was an observational, retrospective cohort study, based on analysis of the continued registration data bank from the intensive care unit (ICU) of the Hospital das Clinicas, State University of Campinas (HC-UNICAMP) and the Transplant Organ Search Organization, in compliance with the Brazilian Federal Medical Council Decision No. 1,480/97, from 2010 to 2017.

In this convenience sample, all consecutively admitted patients eligible for a diagnosis of BD, and with complete clinical records, were included. The inclusion criteria were: age above 13 years, established etiology of coma (Glasgow coma scale = 3 ), absence of severe endocrine and metabolic disorders possibly causing coma, body temperature above $35^{\circ} \mathrm{C}$, hemodynamic stability with systolic blood pressure (SBP) above 90 $\mathrm{mm} \mathrm{Hg}$ (even if under vasoactive drugs), and no sedative, hypnotic and/or neuromuscular blocking drugs [2]. Patients with incomplete clinical records and with a cardiorespiratory arrest before the protocol completion were excluded.

From the initial sample of 102 notifications of BD, 87 protocols were evaluated (Fig. 1). The sample profile was characterized by descriptive statistics of the numerical variables with their respective mean and standard deviation values. Intergroup comparisons were made using the Student's $t$-test. The trial project was approved by the UNICAMP Institutional Ethics Committee (CAAE \#83229417.0.0000.5404). This study was conducted according to the STROBE Statement checklist for cohort studies, the Equator network.

\section{Results}

The study population characteristics are displayed in Table 1. Eighty-seven protocols were evaluated. Within our population, the main age was $42( \pm 16)$ years old and mostly male individuals $66 \%(\mathrm{n}=57)$. The most common coma etiology was traumatic brain injury $(\mathrm{n}=38)$ followed by vascular causes (hemorrhagic stroke, $\mathrm{n}=20$, brain aneurysm, $\mathrm{n}=7$ and ischemic stroke, $\mathrm{n}=7)$. Both sodium ( $\mathrm{Na} 154 \pm 13 \mathrm{mEq} / \mathrm{L})$ and hemoglobin $(\mathrm{Hb})(10 \pm 2 \mathrm{mg} / \mathrm{dL})$ were measured previously in the protocol.

The mean AT duration was $11 \mathrm{~min}$. All of the patients were under vasoactive drugs. Only five ATs were interrupted before the end at $10 \mathrm{~min}$ due to rapid desaturation $\left(\mathrm{SatO}_{2}<90 \%\right)$, with no invalidated AT.

The assessed variables were $\mathrm{pH}, \mathrm{HCO}_{3}, \mathrm{PaO}_{2}, \mathrm{PaCO}_{2}$, and $\mathrm{SatO}_{2}$, both before and after the AT. The differences between the first and second ATs are shown in Figures 2 and 3.

Mean and standard deviation of blood gas tests assessed before the first AT were: $\mathrm{pH} 7.35( \pm 0.10), \mathrm{PaO}_{2} 252.15 \mathrm{~mm}$ $\mathrm{Hg}( \pm 114.11), \mathrm{PaCO}_{2} 42.78 \mathrm{~mm} \mathrm{Hg}( \pm 10.84), \mathrm{HCO}_{3} 22.77$ $\mathrm{mEq} / \mathrm{L}( \pm 3.82), \mathrm{SatO}_{2} 98.77 \%( \pm 2.44)$. After the first AT, we found: $\mathrm{pH} 7.11$ ( \pm 0.08), $\mathrm{PaO}_{2} 208.39 \mathrm{~mm} \mathrm{Hg}( \pm 112), \mathrm{PaCO}_{2}$ $82.43 \mathrm{~mm} \mathrm{Hg}( \pm 16.91), \mathrm{HCO}_{3} 25.2 \mathrm{mEq} / \mathrm{L}( \pm 3.87), \mathrm{SatO}_{2}$ $96.31 \%( \pm 5.41)$. Before the second AT: $\mathrm{pH} 7.33( \pm 0.09)$, $\mathrm{PaO}_{2} 253.56 \mathrm{~mm} \mathrm{Hg}( \pm 105.36), \mathrm{PaCO}_{2} 43.76 \mathrm{~mm} \mathrm{Hg}( \pm$ 9.67), $\mathrm{HCO}_{3} 22.66 \mathrm{mEq} / \mathrm{L}( \pm 3.5), \mathrm{SatO}_{2} 99.09 \%$ ( \pm 1.48$)$. Following the second AT: $\mathrm{pH} 7.11( \pm 0.10), \mathrm{PaO}_{2} 200.1 \mathrm{~mm} \mathrm{Hg}( \pm$ 116.45), $\mathrm{PaCO}_{2} 84.98 \mathrm{~mm} \mathrm{Hg}( \pm 20.21), \mathrm{HCO}_{3} 25.13 \mathrm{mEq} / \mathrm{L}$ $( \pm 3.81), \mathrm{SatO}_{2} 95.14 \%( \pm 6.86)$.

Increased $\mathrm{PaCO}_{2}$ values (above $55 \mathrm{~mm} \mathrm{Hg}$ ) and low $\mathrm{pH}(<$ 7.2) levels were found. The $\mathrm{pH}, \mathrm{PaO}_{2}$, and $\mathrm{PaCO}_{2}$ values before and after the first and second ATs have shown statistically significant differences $(\mathrm{P}<0.0001)$.

\section{Discussion}

During this trial, the diagnosis of BD included two neurological examinations with a minimum 6-h interval, with two ATs following each neurological assessment, and ancillary tests [2]. In December 2017 the Brazilian Federal Medical Council has issued the Decision 2.173; the main changes in this document included reducing to $1 \mathrm{~h}$ the minimal time interval 
Table 1. Population Characteristics

\begin{tabular}{|c|c|}
\hline Characteristics & $\mathbf{N}=87$ \\
\hline \multicolumn{2}{|l|}{ Age, years } \\
\hline Mean & 42 \\
\hline SD & 16 \\
\hline \multicolumn{2}{|l|}{ Sex, n (\%) } \\
\hline Male & $57(66 \%)$ \\
\hline Female & $30(34 \%)$ \\
\hline \multicolumn{2}{|l|}{ Coma etiology, $n$} \\
\hline Traumatic brain injury & 38 \\
\hline Hemorrhagic stroke & 20 \\
\hline Brain aneurysm & 10 \\
\hline Brain tumor & 9 \\
\hline Ischemic stroke & 7 \\
\hline Anoxic encephalopathy & 2 \\
\hline Sepsis & 1 \\
\hline \multicolumn{2}{|l|}{ Sodium (before AT), mEq/L } \\
\hline Mean & 154 \\
\hline $\mathrm{SD}$ & 13 \\
\hline \multicolumn{2}{|l|}{ Hemoglobin, mg/dL } \\
\hline Mean & 10 \\
\hline $\mathrm{SD}$ & 2 \\
\hline \multicolumn{2}{|l|}{ Duration of 1st AT, min } \\
\hline Mean & 11 \\
\hline $\mathrm{SD}$ & 2 \\
\hline \multicolumn{2}{|l|}{ Duration of 2nd AT, min } \\
\hline Mean & 11 \\
\hline SD & 2 \\
\hline \multicolumn{2}{|l|}{ BD protocol duration, $\mathrm{h}$} \\
\hline Mean & 15 \\
\hline $\mathrm{SD}$ & 8 \\
\hline \multicolumn{2}{|l|}{ Use of vasoactive drugs, n (\%) } \\
\hline Yes & $87(100 \%)$ \\
\hline \multicolumn{2}{|l|}{ ICU admission SOFA } \\
\hline Mean & 8 \\
\hline SD & 4 \\
\hline \multicolumn{2}{|l|}{ ICU admission APACHE II } \\
\hline Mean & 20 \\
\hline $\mathrm{SD}$ & 7 \\
\hline \multicolumn{2}{|l|}{ ICU admission SAPS 3} \\
\hline Mean & 54 \\
\hline SD & 15 \\
\hline
\end{tabular}

AT: apnea test; SD: standard deviation; ICU: intensive care unit; SOFA: sequential organ failure assessment; APACHE: acute physiology and chronic health evaluation; SAPS: simplified acute physiology score. between the first and the second clinical assessments and performing one single AT $[4,5]$. It is known that coma patients progressing to $\mathrm{BD}$ have increased catecholamine and cytokine release, in addition to triggering of the inflammatory cascade. These changes disrupt homeostasis, leading to hemodynamic instability and organ dysfunctions. This physiological deterioration may, in case of donation, impact graft viability [6-9]. Additionally, during the AT, to reach the diagnosis of a definitive respiratory center impairment, it is required to increase the $\mathrm{PaCO}_{2}$. Systemic acidosis, required for maximal respiratory center stimulation, causes detrimental hemodynamic effects, such as myocardial depression, hypotension, and arrhythmias [9-15]. The test methodology, either by apneic oxygen diffusion or positive end-expiratory pressure, reduces hypoxemia and desaturations, however, has no impact on $\mathrm{CO}_{2}$ increase $[3,12]$.

Regarding $\mathrm{PaO}_{2}$ pre- and post- the first and second ATs, we found a statistically significant difference $(\mathrm{P}<0.0001)$, however, within the boundaries of safety (Figs. 2, 3). During this study, only five ATs were interrupted, two of them in the same patient, before $10 \mathrm{~min}$ due to rapid desaturation $\left(\mathrm{SatO}_{2}\right.$ $<90 \%$ ). It should be stressed that for safely conducting the AT, some pre-requisites should be in place, such as appropriate medical training $[13,16,17]$, and that some authors as Mascia et al [18] advocate performing AT with continuous positive airway pressure therapy (CPAP), based on less physiological repercussion on the donor-to-be and improved short- and longterm transplanted organs survival [19].

As previously reported, the resulting $\mathrm{PaCO}_{2}$ increase and acidemia may cause detrimental systemic effects. Reduced cardiac contractility (especially with $\mathrm{pH}<7.20$ ), arrhythmias (also due to increased serum potassium), reduced endogenous and exogenous cardiovascular response to catecholamines, increased pulmonary vasoconstriction (increasing right ventricular afterload), in addition to the cell function itself, are mentioned. Studies suggest that a $\mathrm{pH}<7.20$ causes deep inhibition of intracellular phosphokinase production and decreased cellular energy production $[3,20]$.

During the AT, $\mathrm{PaCO}_{2}$ displays a biphasic behavior, with a marked increase during the first minutes, up to $5 \mathrm{~mm} \mathrm{Hg} / \mathrm{min}$ and, later, ranging from $2-3 \mathrm{~mm} \mathrm{Hg} / \mathrm{min}$ [3]. Based on this, one should avoid starting an AT with $\mathrm{PaCO}_{2}$ values below 35 $\mathrm{mm} \mathrm{Hg}$, as it would imply longer apnea time, and therefore, increased exposure to higher $\mathrm{CO}_{2}$ levels and acidemia caused by the respiratory acidosis and the mentioned detrimental effects, added to a risk of hypoxemia [21]. $\mathrm{CO}_{2}$ level may be better assessed by using end-tidal capnometry during the preoxygenation phase, and/or using transcutaneous carbon dioxide partial pressure monitoring, which would provide a better $\mathrm{CO}_{2}$ increase assessment during apnea $[21,22]$.

We found increased $\mathrm{PaCO}_{2}$ values (above $55 \mathrm{~mm} \mathrm{Hg}$ ) and low $\mathrm{pH}(<7.2)$ levels, however with no AT interruption or invalidation due to hemodynamic instability caused by acidemia. It should be noted that $100 \%$ of the patients were under vasoactive drugs (Table 1).

Based on this cohort, we conclude that the AT was safe. The blood gas parameters observed are similar to those mentioned in the literature. We stress that despite the hypercapnia and acidemia observed by the end of the AT, no test was invali- 

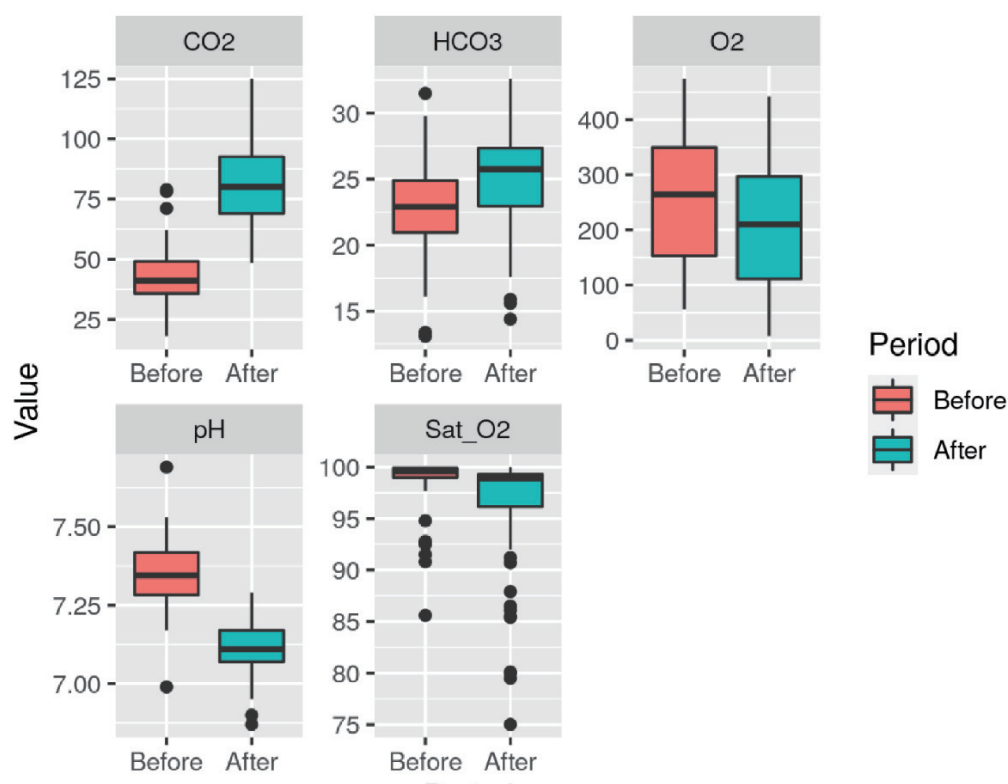

Period

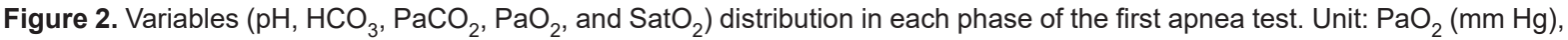
$\mathrm{PaCO}_{2}(\mathrm{mmHg}), \mathrm{HCO}_{3}(\mathrm{mEq} / \mathrm{L})$, SatO $_{2}(\%)$.

dated due to hypotension not responding to vasoactive drugs ( $\mathrm{SBP}<90 \mathrm{~mm} \mathrm{Hg}$ ), arrhythmias or hypoxemia.

This study highlights the safety of the AT. The inclusion of a single AT $[4,5]$ prevents unnecessary exposure to acidemia, hypercarbia, risk of hypoxemia, as well as the risk of cardiovascular and barotrauma complications [23].

This study has limitations. The observational and retrospective design, the lack of objective tests showing myocardial depression, the lack of measuring vasoactive drugs dose changes during the AT, and the lack of description of AT methods, should be mentioned.

\section{Acknowledgments}

We would like to acknowledge the contribution of the Intensive Care Unit and Transplant Organ Search Organization multidisciplinary teams, especially Claudineia Logatto, Ra-
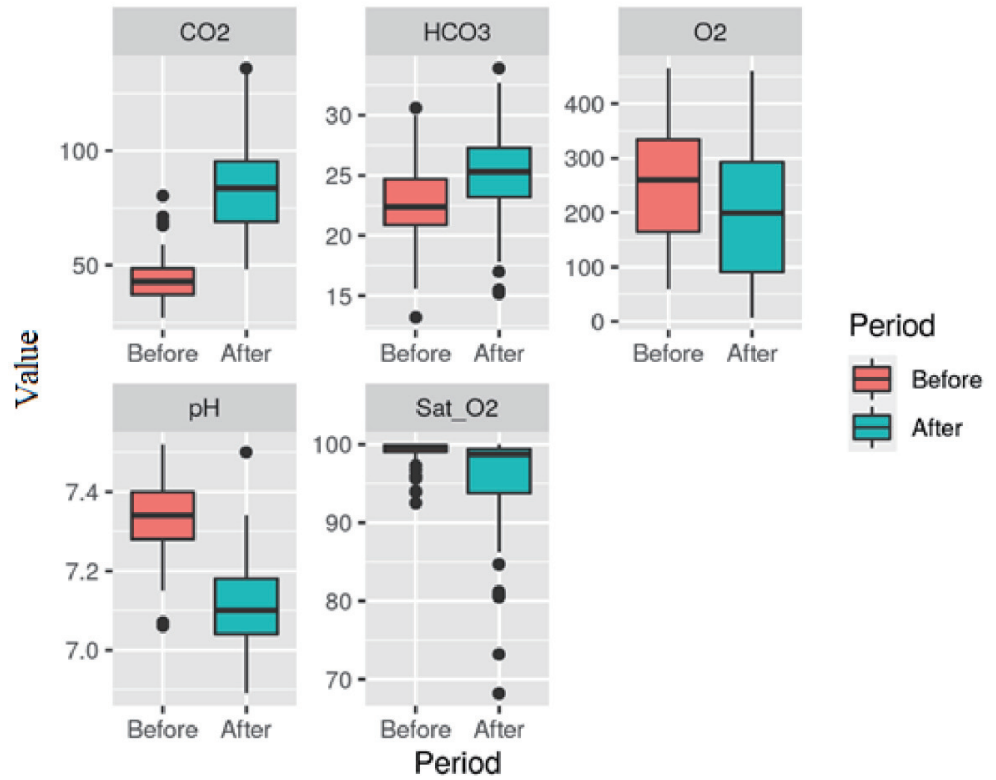

Figure 3. Variables $\left(\mathrm{pH}, \mathrm{HCO}_{3}, \mathrm{PaCO}_{2}, \mathrm{PaO}_{2}\right.$, and $\left.\mathrm{SatO}_{2}\right)$ distribution in each phase of the second apnea test. Unit: $\mathrm{PaO}_{2}\left(\mathrm{~mm}^{2}\right.$ $\mathrm{Hg}), \mathrm{PaCO}_{2}(\mathrm{mmHg}), \mathrm{HCO}_{3}(\mathrm{mEq} / \mathrm{L}), \mathrm{SatO}_{2}(\%)$. 
faela Batista dos Santos Pedrosa, Klenio de Oliveira Bonfim, Luciana Aparecida dos Santos, and Maria Valeria de Omena Athayde.

\section{Financial Disclosure}

This study had no funding source.

\section{Conflict of Interest}

No conflict of interest to be reported.

\section{Informed Consent}

Ethical clearance for such a retrospective analysis was provided by the institutional ethical committee but informed consent was not asked. The data were collected secondarily through the database and medical records and not directly with individuals or family members, in this way, respecting confidentiality, without causing harm to the patient or institution.

\section{Author Contributions}

TS conceived and designed the study, analyzed the data, and with NN's contribution wrote the first and revised version of the manuscript. GF contributed to the study data analysis and interpretation. $\mathrm{RM}$ and $\mathrm{AB}$ contributed to reviewing critically data analysis and manuscript. VF, HZ, APG, and LAS contributed with manuscript writing and revision. ALF contributed substantially to important intellectual content with study design, manuscript writing, revision, and final approval of the version to be published. All authors read and approved the final manuscript.

\section{Data Availability}

The authors declare that data supporting the findings of this study are available within the article.

\section{References}

1. A definition of irreversible coma. Report of the Ad Hoc Committee of the Harvard Medical School to examine the definition of brain death. JAMA. 1968;205(6):337-340.

2. Conselho Federal de Medicina, Resolucao CFM no 1.480/1997. https://sistemas.cfm.org.br/normas/visualizar/resolucoes/BR/1997/1480.

3. Solek-Pastuszka J, Biernawska J, Iwanczuk W, Kojder K, Chelstowski K, Bohatyrewicz R, Sawicki M. Comparison of two apnea test methods, oxygen insufflation and continuous positive airway pressure during diagnosis of brain death: final report. Neurocrit Care. 2019;30(2):348-354.
4. Conselho Federal de Medicina, Resolucao CFM no 2.173/2017. https://sistemas.cfm.org.br/normas/visualizar/resolucoes/BR/2017/2173.

5. Westphal GA, Veiga VC, Franke CA. Diagnosis of brain death in Brazil. Rev Bras Ter Intensiva. 2019;31(3):403409.

6. Opdam HI. Hormonal Therapy in Organ Donors. Crit Care Clin. 2019;35(2):389-405.

7. Jennett B, Gleave J, Wilson P. Brain death in three neurosurgical units. Br Med J (Clin Res Ed). 1981;282(6263):533539.

8. Wijdicks EF. Management of the comatose patient. Handb Clin Neurol. 2017;140:117-129.

9. Scott JB, Gentile MA, Bennett SN, Couture M, MacIntyre NR. Apnea testing during brain death assessment: a review of clinical practice and published literature. Respir Care. 2013;58(3):532-538.

10. Lang CJ, Heckmann JG. Apnea testing for the diagnosis of brain death. Acta Neurol Scand. 2005;112(6):358-369.

11. Shutter L. Pathophysiology of brain death: what does the brain do and what is lost in brain death? J Crit Care. 2014;29(4):683-686.

12. Datar S, Fugate J, Rabinstein A, Couillard P, Wijdicks EF. Completing the apnea test: decline in complications. Neurocrit Care. 2014;21(3):392-396.

13. Salih F, Hoffmann O, Brandt SA, Masuhr F, Schreiber S, Weissinger F, Rocco A, et al. Safety of apnea testing for the diagnosis of brain death: a comprehensive study on neuromonitoring data and blood gas analysis. Eur J Neurol. 2019;26(6):887-892.

14. Russell JA. Author response: Brain death, the determination of brain death, and member guidance for brain death accommodation requests: AAN position statement. Neurology. 2019;93(21):948.

15. Daneshmand A, Rabinstein AA, Wijdicks EFM. The apnea test in brain death determination using oxygen diffusion method remains safe. Neurology. 2019;92(8):386387.

16. Bernat JL, Brust JCM. Strategies to improve uniformity in brain death determination. Neurology. 2019;92(9):401402.

17. Braksick SA, Robinson CP, Gronseth GS, Hocker S, Wijdicks EFM, Rabinstein AA. Variability in reported physician practices for brain death determination. Neurology. 2019;92(9):e888-e894.

18. Mascia L, Pasero D, Slutsky AS, Arguis MJ, Berardino M, Grasso S, Munari M, et al. Effect of a lung protective strategy for organ donors on eligibility and availability of lungs for transplantation: a randomized controlled trial. JAMA. 2010;304(23):2620-2627.

19. Michel SG, Madariaga MLL, LaMuraglia GM, 2nd, Villani V, Sekijima M, Farkash EA, Colvin RB, et al. The effects of brain death and ischemia on tolerance induction are organ-specific. Am J Transplant. 2018;18(5):12621269.

20. Powner DJ, Kellum JA. Maintaining acid-base balance in organ donors. Prog Transplant. 2000;10(2):98-103; quiz 104-105.

21. Busl KM, Lewis A, Varelas PN. Apnea Testing for the 
Determination of Brain Death: A Systematic Scoping Review. Neurocrit Care. 2020.

22. Vivien B, Marmion F, Roche S, Devilliers C, Langeron O, Coriat P, Riou B. An evaluation of transcutaneous carbon dioxide partial pressure monitoring during apnea testing in brain-dead patients. Anesthesiology. 2006;104(4):701707.

23. Goudreau JL, Wijdicks EF, Emery SF. Complications during apnea testing in the determination of brain death: predisposing factors. Neurology. 2000;55(7):1045-1048. 